\title{
Electromyographic (EMG) Study of the Elbow Flexors during Supination and Pronation of the Forearm
}

\author{
Akira Naito, Michiniro Yajima*, Hidehiko \\ Fukamachi*, KoJi Ushikoshi†, YING-Jie Sun and \\ Yoshifusa Shimizu \\ Department of Anatomy, Shinshu University School of \\ Medicine, Matsumoto 390, *Kosei-Ren Kakeyu-Misayama \\ Hospital, Maruko-Machi 386-03, and †Aizawa Hospital, \\ Matsumoto 390
}

Naito, A., Yajima, M., Fukamachi, H., Ushikoshi, K., Sun, Y.-J. and Shimizu, Y. Electromyographic (EMG) Study of the Elbow Flexors during Supination and Pronation of the Forearm. Tohoku J. Exp. Med., 1995, 175 (4), 285-288 - Activities of the elbow flexors during supination and pronation of the forearm in a normal human volunteer were studied by an electromyography (EMG). The volunteer performed the movement slowly or quickly holding elbow flexion at various angles with or without a load. The biceps brachii showed an increase and a decrease of EMG activities during supination and pronation, respectively. The brachialis and brachioradialis showed a reduction and an increment of EMG activities accompanied by an increase and a decrease of EMG activities in the biceps brachii, respectively. These findings seem to indicate that reciprocal contractions among the elbow flexors permit the biceps brachii to work for supination without an induction of elbow flexion. - biceps brachii; brachialis; brachioradialis; supination and pronation; electromyography (EMG)

The biceps brachii is acting as the elbow flexor and forearm supinator. We have confirmed that electrical activations of the muscle resulted in simultaneous inductions of flexion and supination in normal human volunteers and $\mathrm{C} 4$ quadriplegic patients (Naito et al. 1994a, b). On the other hand, our electromyographic (EMG) study of supination without any flexion indicated that activities of the biceps brachii increased with supinating the forearm (Naito et al. 1994a). Since these activities work for not only supination but also flexion, it seems that changes of the other muscles activities should occur to prevent an induction of flexion. In this study, we demonstrated clear reductions of the brachialis and brachioradialis activities accompanied with the increase of the biceps brachii activities using EMG.

EMGs of the elbow flexors (long and short heads of the biceps brachii, the brachialis, the brachioradialis) were recorded from a human volunteer (female, 22 years of ages). Bipolar wire electrodes were implanted percutaneously into the muscles. Details of experimental procedures for EMG recording have been described previously (Naito et al. 1994a). EMGs were amplified, rectified and averaged for analysis.

A movement tested was a to-and-fro motion from prone to supine position of the

Received September 16, 1994; revision accepted for publication January 10, 1995. 
forearm (PS-movement) while keeping the elbow joint in various angles of flexion (the maximum extension, 30, 60 and 90 degrees of flexion). In this study, the prone and supine positions indicated about 90 degrees of pronation and supination in the forearm, respectively. Thus the range of PS-movement was about 180 degrees (from 90 degrees of pronation to 90 degrees of supination). She performed the movement slowly or quickly with or without holding a load (a cylindrical object weighing of $1.2 \mathrm{~kg}$ ) in the hand. In the slow movement, each motion of supination and pronation was started at an experimenter's call and finished in around $8 \mathrm{sec}$. When supination was ended she kept the forearm supine for several seconds before pronation was started. In the quick movement, a series of 10 PS-movements were started at the call and finished in around 15 sec. The movement was performed more than 2 times in each experimental situation. During the experiment, she was sitting on a chair and keeping the upper arm on a table with the shoulder joint flexed to about 90 degrees. A potentiometer was used for indicating which motion was performed, supination or pronation (Naito et al. 1994a).

When the forearm was pronated before and after the PS-movement, the biceps brachii showed slight or no EMG activities and the brachialis and brachioradialis showed an amount of EMG activities (Figs. 1, 2). During the movement, the biceps brachii showed an increase and a decrease of EMG activities with increasing and decreasing the degree of supination, respectively. On the contrary, EMG activities of the brachialis and brachioradialis decreased accompanied with an increment of EMG activities in the biceps brachii. These fluctuations provided alternating increases of EMG activities between the biceps brachii and the other flexors during the quick movement (Fig. 2). Although a quantity and

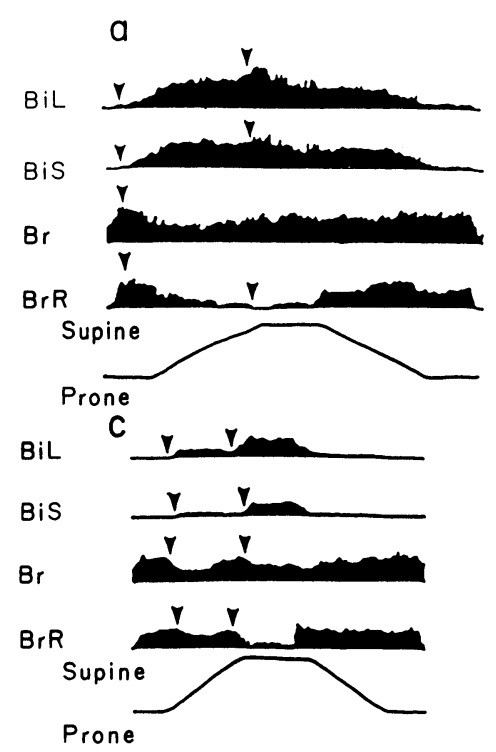

b
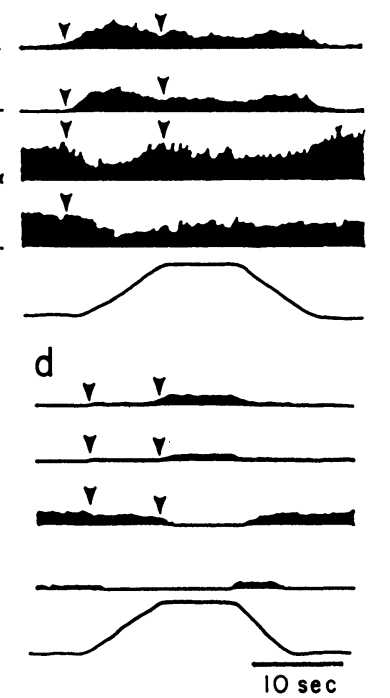

Fig. 1. Averaged EMGs of the elbow flexors during a slow to-and-fro motion from prone to supine of the forearm (PS-movement) with keeping the elbow joint in the maximum extension (a), and $30(b, d)$ and 60 degrees (c) of flexion. a, b, c: PS-movement with a load. d: PS-movement without a load. Solid lines indicate changes in a position of the forearm. Note that clear reductions of $\mathrm{Br}$ or $\mathrm{BrR}$ activities were observed accompanied with increases of $\mathrm{BiL}$ or BiS activities (arrow heads). BiL and BiS, long and short heads of the biceps brachii; $\mathrm{Br}$, the brachialis; $\mathrm{Br}$, Rthe brachioradialis. 


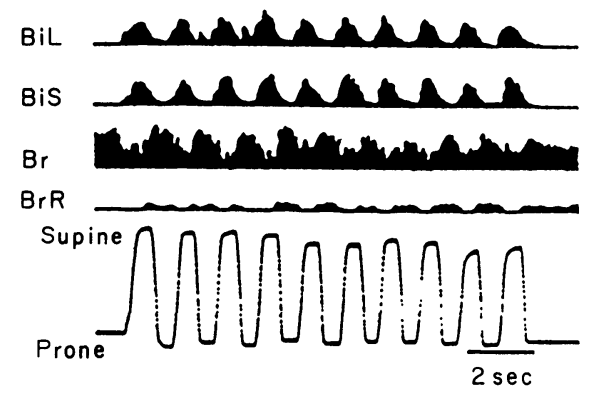

Fig. 2. Averaged EMGs of the elbow flexors during a series of quick PSmovements without a load at the elbow joint flexed to 90 degrees. A solid line at the bottom of the figure indicates changes in a position of the forearm. $\mathrm{BiL}$ and $\mathrm{BiS}$, long and short heads of the biceps brachii; $\mathrm{Br}$, the brachialis; $\mathrm{BrR}$, the brachioradialis.

a fluctuation of EMG activities in individual muscles varied by experimental situations (Figs. 1-a, b, c, d), these phenomena were always seen during the movement.

It is described in some textbooks of anatomy that the triceps brachii contracts when the biceps brachii is used for supination without any flexion (Gardner 1960; Lockhart 1964; Joseph 1976). In contrast, Sinclair (1981) describes that flexion and supination occur together when the biceps brachii contracts, and unwanted one is canceled out by the synergists. The present study clearly demonstrated reciprocal contractions between the biceps brachii and the other flexors during the PS-movement. Furthermore, our recent EMG study using other apparatuses, which enabled us to indicate an EMG signal-force relationship, found that the triceps brachii did not show any EMG activities during the PS-movement in normal human volunteers (Naito et al. 1994c). It therefore seems likely that changes of activities in the synergists, not in the antagonists, permit the biceps brachii to work for supination without an induction of flexion.

It is well known that the biceps brachii becomes less active on the prone forearm (Beevor 1903; Sullivan et al. 1950; Basmajian and Latif 1957; Basmajian and Deluca 1985; Naito et al. 1991, 1994a). In this regard, Basmajian and Latif (1957) speculated that some afferent impulses from the pronators might inhibit the biceps brachii activities. This speculation is seen to be described from the reciprocal inhibition mechanism between the antagonist muscles. On the other hand, our electrophysiological studies using post-stimulus time histograms found reciprocal inhibitory effects between the biceps brachii and brachioradialis (Miyasaka et al. 1994). Considering the results of the present study, it is thought that some ingenious reciprocal relationships exist among the elbow flexors.

\section{Acknowledgment}

We wish to thank Mr. Michio Miyata, Miss Kumiko Yokouchi and Miss Maki Asano for their excellent assistance. Thanks are also tendered to students of Shinshu University School of Medicine for their cooperation.

\section{References}

1) Basmajian, J.V. \& Latif, A. (1957) Integrated actions and functions of the chief flexors of the elbow. J. Bone Joint Surg., 39-A, 1106-1118.

2) Basmajian, J.V. \& Deluca, C.J. (1985) Muscle Alive: Their Functions Revealed by Electromyography. 5th ed., William and Wilkins, Baltimore, pp. 265-289.

3) Beevor, C.E. (1903) Croonian lectures on muscular movements and their representa- 
tion in the central nervous system. Lancet, 1, 1715-1724.

4) Gardner, E. (1960) Chapter 14. Arm and Elbow. In: Anatomy: A Regional Study of Human Structure, edited by E. Gardner, D.J. Gray \& R. O'Rahilly, W.B. Saunders, Philadelphia, London, pp. 167-168.

5) Joseph, J. (1976) Fascia and muscles of the upper limb. In: Textbook of Human Anatomy, 2nd ed., edited by W.J. Hamilton, Macmillan Press, London Basingstoke, p. 169.

6) Lockhart, R.D. (1964) Muscle of the upper limb. In: Cunningham's Textbook of Anatomy, 10th ed., edited by G.J. Romanes, Oxford University Press, London, pp. 328-329.

7) Miyasaka, T., Sun, Y.-J., Naito, A., Morita, H., Shindo, M., Shimizu, Y. \& Yanagisawa, N. (1994) Reciprocal inhibition between two elbow flexors in the human. Neurosci. Res., Suppl., 19, 193.

8) Naito, A., Shimizu, Y., Handa, Y., Ichie, M. \& Hoshimiya, N. (1991) Functional anatomical studies of the elbow movements I. Electromyographic (EMG) analysis. Okajimas Folia Anat. Jpn., 68, 283-288.

9) Naito, A., Yajima, M., Fukamachi, H., Ushikoshi, K., Handa, Y., Hoshimiya, N. \& Shimizu, Y. (1994a) Electrophysiological studies of the biceps brachii activities in supination and flexion of the elbow. Tohoku J. Exp. Med., 173, 259-267.

10) Naito, A., Yajima, M., Fukamachi, H., Ushikoshi, K., Handa, Y., Hoshimiya, N. \& Shimizu, Y. (1994b) Functional electrical stimulation (FES) to the biceps brachii for controlling forearm supination in the paralyzed upper extremity. Tohoku J. Exp. Med., 173, 269-273.

11) Naito, A., Sun, Y.-J. \& Shimizu, Y. (1994c) Electromyographic activities of the elbow flexors and extensors during forearm supination and pronation movements. In: Abstract, 14th International Congress of Anatomist, p. 572.

12) Sinclair, D.C. (1981) Muscle of the upper limb. In: Cunningham's Textbook of Anatomy, 12th ed., edited by G.J. Romanes, Oxford University Press, Oxford, New York, Toronto, p. 323.

13) Sullivan, W.E., Mortensen, O.A., Miles, M. \& Green, L.S. (1950) Electromyographic studies of $\mathrm{m}$. biceps brachii during normal voluntary movement at the elbow. Anat. Rec., 107, 243-252. 